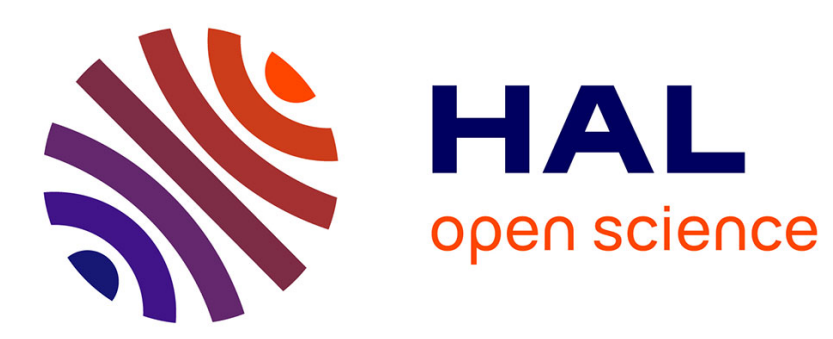

\title{
Electromagnetic emissions from electrical rotating machinery
}

P. Ferrari, Andrea Mariscotti, A. Motta, P. Pozzobon

\section{To cite this version:}

P. Ferrari, Andrea Mariscotti, A. Motta, P. Pozzobon. Electromagnetic emissions from electrical rotating machinery. IEEE Transactions on Energy Conversion, 2001, 16 (1), pp.68-73. 10.1109/60.911406 . hal-02970383

\section{HAL Id: hal-02970383 \\ https://hal.science/hal-02970383}

Submitted on 18 Oct 2020

HAL is a multi-disciplinary open access archive for the deposit and dissemination of scientific research documents, whether they are published or not. The documents may come from teaching and research institutions in France or abroad, or from public or private research centers.
L'archive ouverte pluridisciplinaire HAL, est destinée au dépôt et à la diffusion de documents scientifiques de niveau recherche, publiés ou non, émanant des établissements d'enseignement et de recherche français ou étrangers, des laboratoires publics ou privés. 


\title{
Electromagnetic emissions from electrical rotating machinery
}

\author{
P. Ferrari, A. Mariscotti, *A. Motta, P. Pozzobon \\ Dipartimento di Ingegneria Elettrica \\ Via dell’Opera Pia, 11A - 16145 Genova - Italia \\ *Ansaldo Energia S.p.A. \\ Via N. Lorenzi, 8 - 16152 Genova - Italia
}

P. Ferrari, A. Mariscotti, A. Motta, P. Pozzobon, “Electromagnetic emissions from electrical rotating machinery,” IEEE

Transactions on Energy Conversion, Vol. 16, No. 1, Mar 2001, pp. 68-73. doi: 10.1109/60.911406

\begin{abstract}
The problem of evaluation of the electromagnetic emissions from large power electrical rotating machinery is considered. The results of three measurement campaigns are reported: emissions are correlated with the operating conditions and the characteristics of the machine under test. The measured electric and magnetic field spectra are treated so that they may be used as a reference for preliminary evaluation on similar machines.
\end{abstract}

\section{INTRODUCTION}

Only recently electrical rotating machinery has been considered as a source of electromagnetic emissions other than the magnetic field at the supply frequency and its harmonics. Few contributions may be found in the literature, all concentrated in the last five years [1, 2]. Large power electrical rotating machinery may be an important source of emissions both internally generated and fed by the supply network and the static converter. The knowledge of the behaviour of these machines at relatively high frequencies is scarce, because most often the design process evaluates only machine inductances at the fundamental and its harmonics. Moreover, the sources of high frequency disturbances (like commutation and arcing in collector machines, modulation phenomena, stray currents through the shaft) and their contribution to machine emissions are a relatively new matter. Yet, electrical drives and generators are to be considered as products, with the need of EMC product standards, which define the target electromagnetic environment, the test procedures and the limits. The test procedures and limits proposed in the amendment A2 to EN 60034-1 [3] are limited to the high frequency range (above $30 \mathrm{MHz}$ ) and are derived from other EMC standards, which are not strictly applicable [4]. No limits are given for medium frequency emissions in the $[9 \mathrm{kHz}, 30 \mathrm{MHz}$ ] frequency range.

Medium frequency emissions in the space surrounding the machine are in the reactive near field region; the coupling to victim circuits is mainly inductive for this class of machines [5] and suitable limits are limits on the $\mathrm{H}$-field intensity.

The measurement of emissions from large power electrical rotating machinery poses a series of problems: the source of emissions is quite extended in space, both in the direction of emissions and in the orthogonal plane; these machines often require several auxiliary systems (supply line, feeding static converters, electric/mechanic load, lubricating and cooling system, etc.), whose contribution to the electromagnetic noise cannot be separated; the test site is far from being similar to an Open Area Test Site (as described by CISPR 16 [6]), for the ground clearly imperfect (concrete, steel, etc.) and for the presence of reflecting and scattering surfaces inside the ideal ellipse; the test conditions are sometimes critical and the machine operating conditions cannot be held constant over the whole interval of time required for the sweep of the entire frequency range.

\section{GENERAL FRAMEWORK}

The performed measurements of electromagnetic emissions consist of separate measurements of the electric and magnetic fields from three different machines: a dc motor, a separately excited synchronous generator and a brushless synchronous generator (their characteristics are detailed in the following sections). The machines have been tested in the Generator Test Room at Ansaldo Energia, Genova, Italy.

Measurements are performed over the $[9 \mathrm{kHz}, 30 \mathrm{MHz}]$ frequency range at different distances from the machine under test.

Industrial EMC standards [4] and the EN 60034-1 [3] consider the [30 MHz, $1 \mathrm{GHz}$ ] frequency range for limits on emissions (radiated field).

The medium frequency range $[9 \mathrm{kHz}, 30 \mathrm{MHz}]$ is chosen, as it is done also in the railways EMC standards [7], on the basis of the considerations done in the introduction.

Emissions below $9 \mathrm{kHz}$ are not considered here, since first, they are not treated by industrial EMC standards and second, they are much more specific and depend on machine characteristics, so that it is very difficult to derive results of general validity.

Throughout the measurements, reasoning has been made on dependence of field intensity on distance and machine load, evidence of characteristic spectral components, etc. Before and during all measurement campaigns, the ambient electromagnetic noise has been measured (see section III).

The results are useful not only to evaluate the electromagnetic emissions of similar machines, but also to locate the most significant sources of emissions, to understand the measurement related problems (described in the Introduction) and to draw rules to extend the results to other electrical rotating machines.

Several readings are performed for each test, so the displayed spectra are the result of averaging, to cancel spurious emissions. 
The used measuring instruments are described in Table I.

TABLE I

MEASURING INSTRUMENTS

\begin{tabular}{|c|c|}
\hline \multicolumn{2}{|l|}{ RF receiver } \\
\hline $\begin{array}{l}\text { Bandwidth } \\
\text { Sensitivity }\end{array}$ & $\begin{array}{c}9 \mathrm{kHz}-30 \mathrm{MHz} \\
12 \mathrm{~dB} \mu \mathrm{V}\end{array}$ \\
\hline \multicolumn{2}{|c|}{ Loop antenna ( $\mathrm{H}$ field) } \\
\hline Bandwidth & $9 \mathrm{kHz}-30 \mathrm{MHz}$ \\
\hline \multicolumn{2}{|c|}{ Rod antenna (E field) } \\
\hline Bandwidth & $9 \mathrm{kHz}-30 \mathrm{MHz}$ \\
\hline
\end{tabular}

The receiver bandwidth is fixed to $200 \mathrm{~Hz}$ for the $9 \mathrm{kHz}-150 \mathrm{kHz}$ and $9 \mathrm{kHz}$ for the $150 \mathrm{kHz}-30 \mathrm{MHz}$ ranges respectively.

The E-field (the average field $\hat{E}$ and the $3 \sigma$ limits $E_{3 \sigma}$ below and above $\hat{E}$ ) and the H-field (the average field $\hat{\mathrm{H}}$ ) along five orientations (the vertical component and four different orientations parallel to ground at $0^{\circ}, 45^{\circ}$, $90^{\circ}$ and $135^{\circ}$ ) were measured.

\section{AMBIENT NOISE \\ IN THE GENERATOR TEST ROOM}

As it was said in the Introduction, large power rotating machinery often require several auxiliary systems, which contribute greatly to the total electromagnetic ambient noise. A preliminary evaluation of the ground noise is very important to determine the minimum measurable emission level and hence, the best positions and the maximum measuring distance.

A sketch of the Generator Test Room, where all the three machines were tested, is shown in Figure 1.

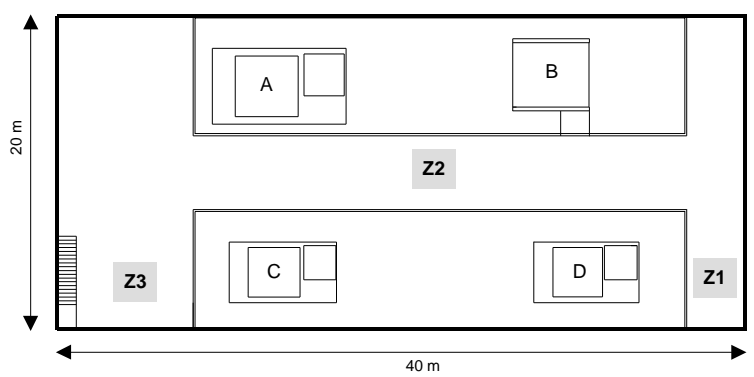

Figure 1: Map of the Generator Test Room

$\mathrm{E}$ - and $\mathrm{H}$ - fields have been measured in the three areas indicated as Z1, Z2 and Z3. The four letters A, B, C and $\mathrm{D}$ indicate the four platforms where the machines are set-up for tests. The ground noise was measured with the auxiliary services in normal operation.

The ambient noise for areas $\mathrm{Z} 2$ and $\mathrm{Z3}$ (where the Eand $\mathrm{H}$-field measurements will be performed) is shown in Figure 2 through 5. The $\mathrm{H}$-field spectra for the five antenna orientations are plotted all together to produce a graphical cumulative effect.
The spectra refer to the noise in normal conditions; several readings were performed in each area, so the displayed spectra are the result of averaging operation.
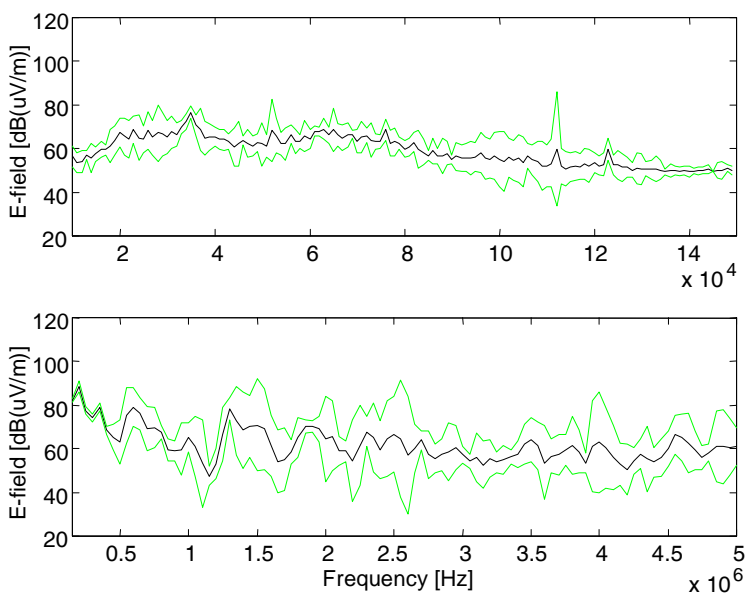

Figure 2: $\hat{\mathrm{E}}$ and $\mathrm{E}_{3 \sigma}$ in $\mathrm{Z} 2$
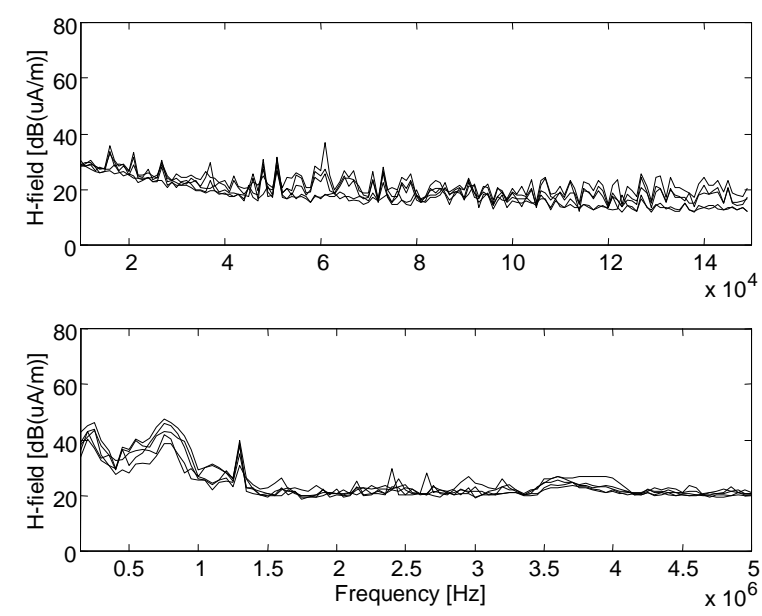

Figure 3: $\hat{\mathrm{H}}$ in $\mathrm{Z} 2$
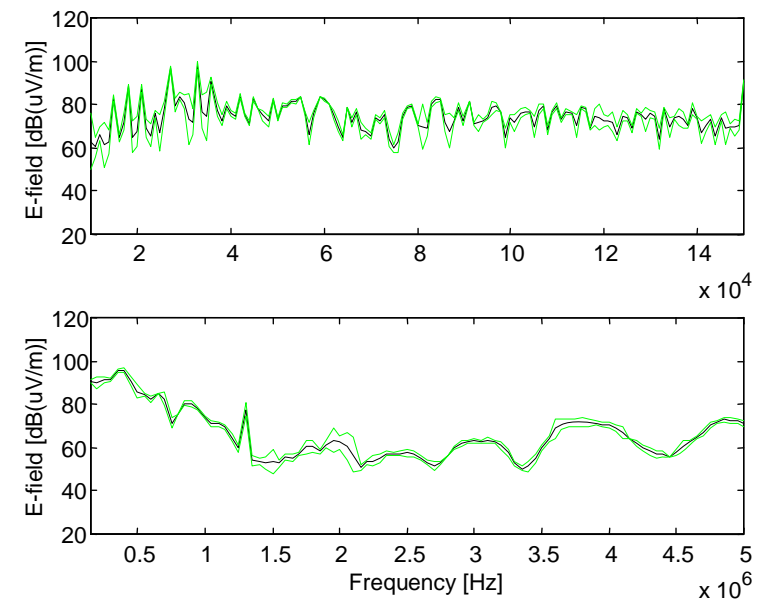

Figure 4: $\hat{E}$ and $E_{3 \sigma}$ in $\mathrm{Z3}$ 

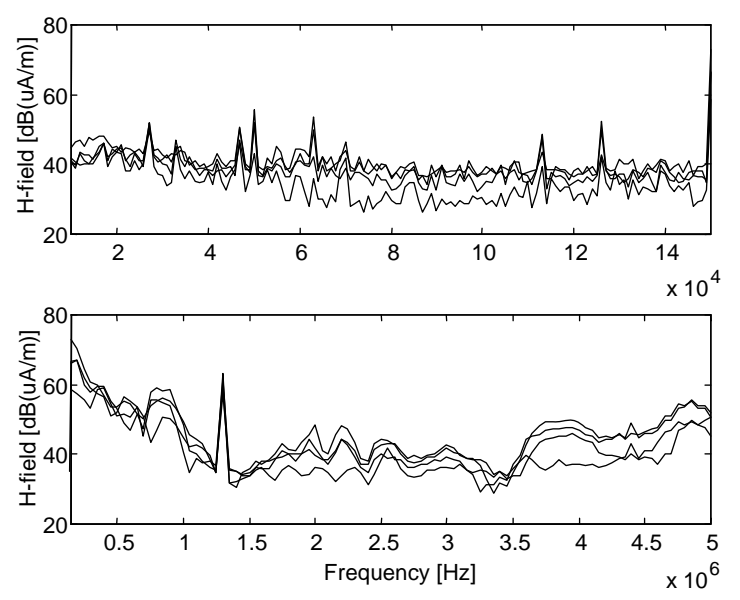

Figure 5: $\hat{\mathrm{H}}$ in $\mathrm{Z3}$

In the $\mathrm{Z3}$ area the ambient noise is a little higher and this is explained, being this zone close to static converters, UPS and lubricating pumps.

In the $\mathrm{Z} 2$ area higher dispersion may be noticed around $\widehat{\mathrm{E}}$, especially at low frequency, with extreme values which are still lower than those in Z3.

Exceptional phenomena like the startup of the lubricating auxiliary system and the use of the bridgecrane must be monitored, since these events produce emissions which are comparable with the machine emissions.

\section{EMISSIONS FROM DC MOTOR}

The dc motor characteristics are reported in Table II.

TABLE II

DC MOTOR RATED VALUES (DC_M)

\begin{tabular}{|l|c|}
\hline Rated power [kW] & 6000 \\
Rated armature voltage [V] & 1200 \\
Rated armature current [A] & 5240 \\
Rated field voltage [V] & 200 \\
Rated field current [A] & 155 \\
Rated speed [rpm] & 530 \\
\hline
\end{tabular}

The dc motor is placed in position $\mathrm{C}$ and the feeding dc generator between $\mathrm{C}$ and $\mathrm{D}$ (see Figure 1). A1, A2 and A3 indicate the measuring points.

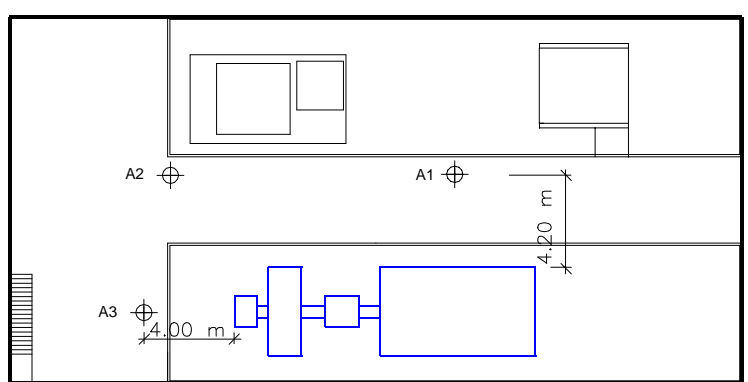

Figure 6: Place of the dc motor and measuring points

The E- and H-field emissions from the DC machine are shown in Figure 7 and 8 respectively. For the H-field spectra, five orientations of the loop antenna are condensed in one picture, labelling each curve separately (the vertical $\mathrm{H}$-field component is in grey).
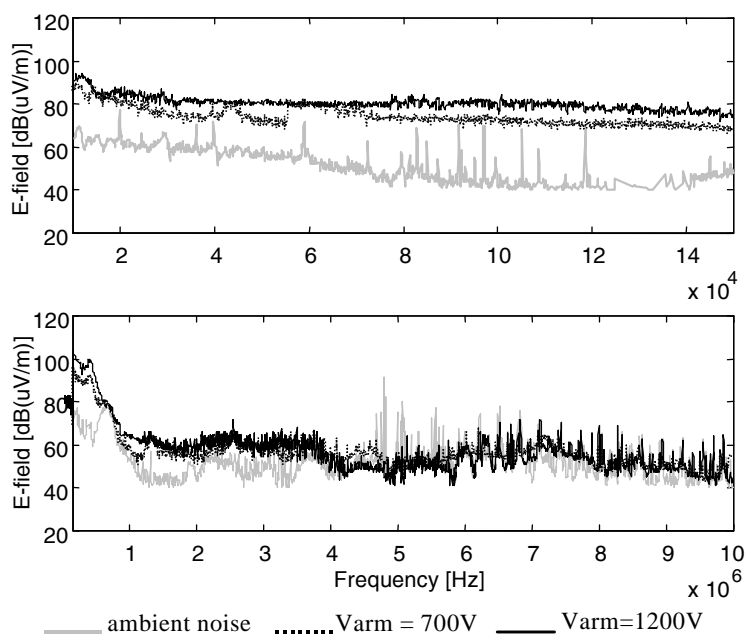

Figure 7 DC_G: E-field at pos. A2 (5.5 m distance) 

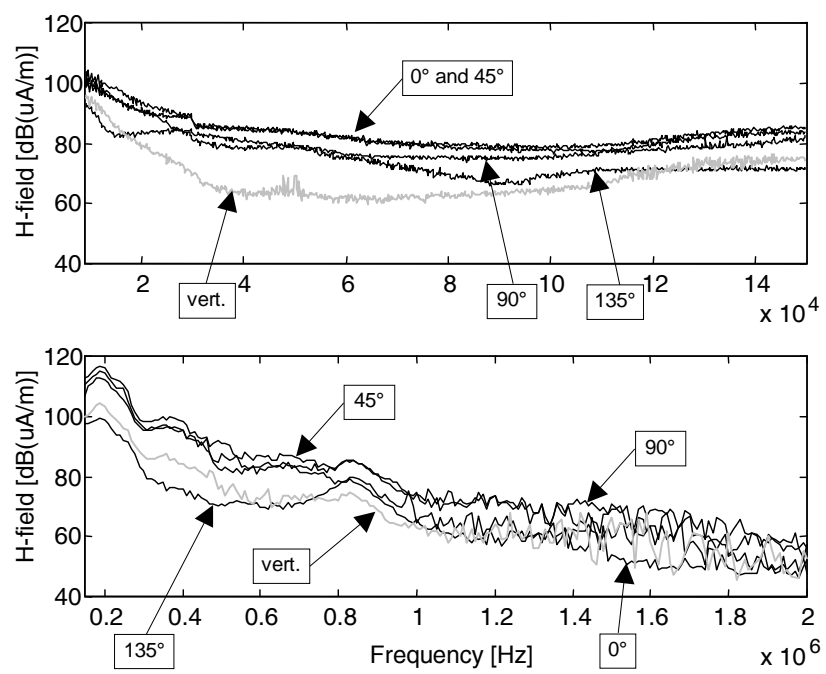

Figure 8 DC_G: H-field at A3 (4 m distance); horizontal $\left(0^{\circ}, 45^{\circ}, 90^{\circ}\right.$ and $\left.135^{\circ}\right)$ and vertical (grey curve) components.

Other measurements at A3 show a reduction of the measuring distance from $4 \mathrm{~m}$ to $3 \mathrm{~m}$ caused an increase of nearly $10 \mathrm{~dB}$ of the $\mathrm{H}$-field values at low frequency (below $50 \mathrm{kHz}$ ): this confirms that the dependence of the $\mathrm{H}$-field intensity on the distance is nearly $1 / \mathrm{d}^{3}$.

Figure 9 shows the measured $\mathrm{H}$-field at $\mathrm{A} 3$ with the dc machine at no-load and at 50\% load.
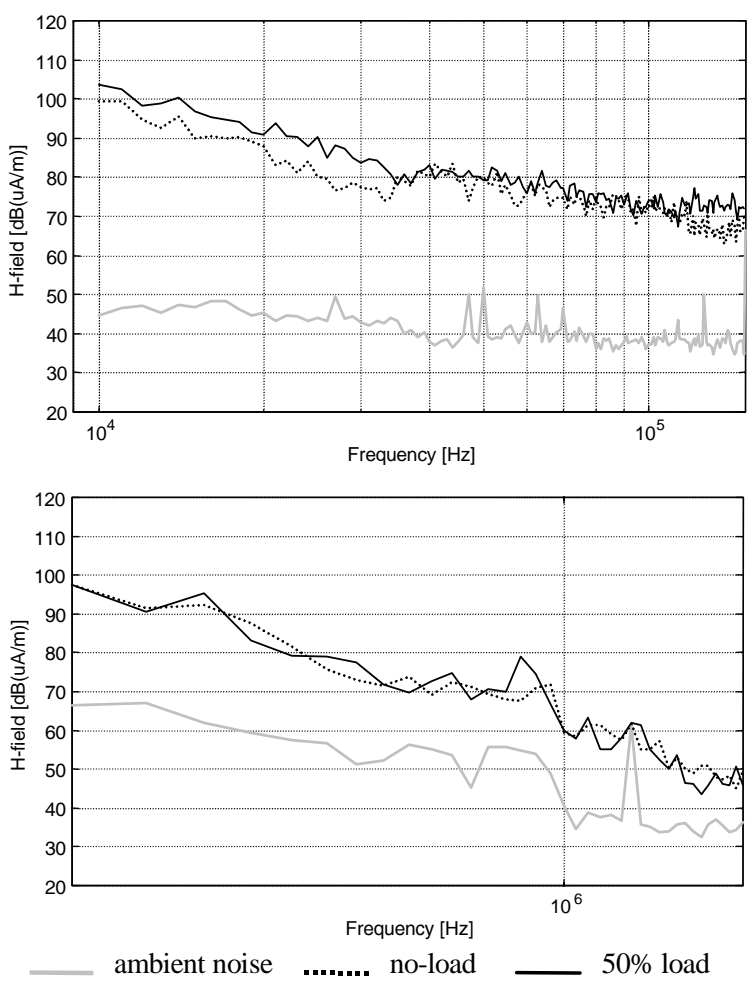

Figure 9: DC_G: H-field at pos. A3 (4.0 m distance)

The H-field emissions are higher for the "50\% load" condition only at low frequency; generally $\mathrm{H}$-field emissions decrease with frequency by more than 20 $\mathrm{dB} /$ decade.

\section{EMISSIONS FROM SEPARATELY EXCITED SYNCHRONOUS GENERATOR}

The generator characteristics are reported in Table III.

TABLE III

SYNCHRONOUS GENERATOR RATED VALUES (SE_G)

\begin{tabular}{|l|c|}
\hline Rated power [MVA] & 205 \\
Rated armature voltage [V] & 15000 \\
Rated armature current [A] & 7890 \\
Rated field voltage [V] & 295 \\
Rated field current [A] & 1361 \\
Rated speed [rpm] & 3000 \\
Rated frequency [Hz] & 50 \\
\hline
\end{tabular}

The driving dc motor is placed in position A (see Figure 1) and the synchronous motor between A and B.

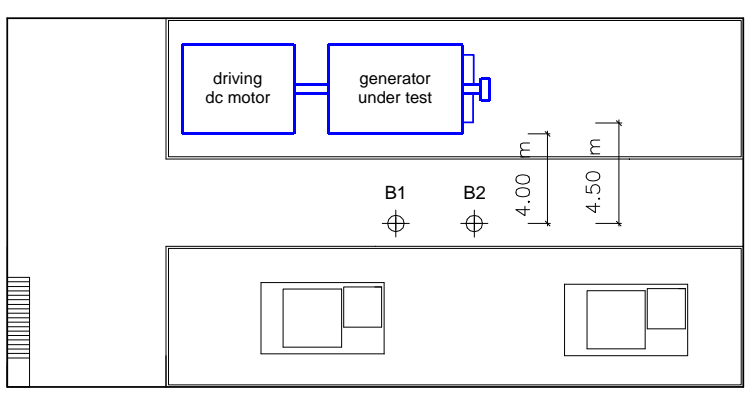

Figure 10: Place of the generator and measuring points

From early measurements it was clear for this kind of machine that the electric field emissions may be neglected, being less than or comparable with those from the driving dc motor. Hence, no electric field measurements were performed on the brushless synchronous generator, described in the next section.

Three tests are considered: the generator is only moved by the driving dc motor; the generator is tested in no- 
load condition (field circuit values: $\mathrm{V}_{\mathrm{f}}=90 \mathrm{~V}$ and $\mathrm{I}_{\mathrm{f}}=496$ $\mathrm{A}$ ); the generator is tested in short circuit (field circuit values: $\mathrm{V}_{\mathrm{f}}=175 \mathrm{~V}$ and $\mathrm{I}_{\mathrm{f}}=953 \mathrm{~A}$ ).

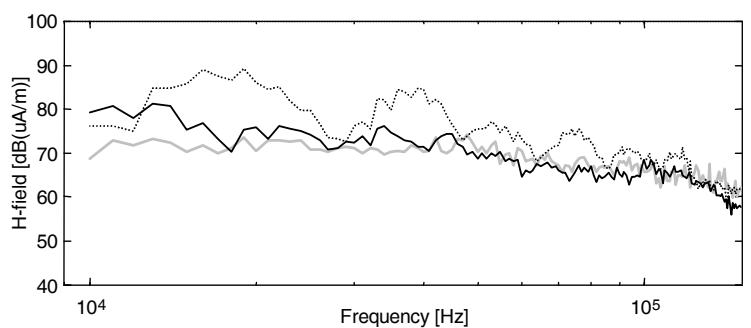

(a)

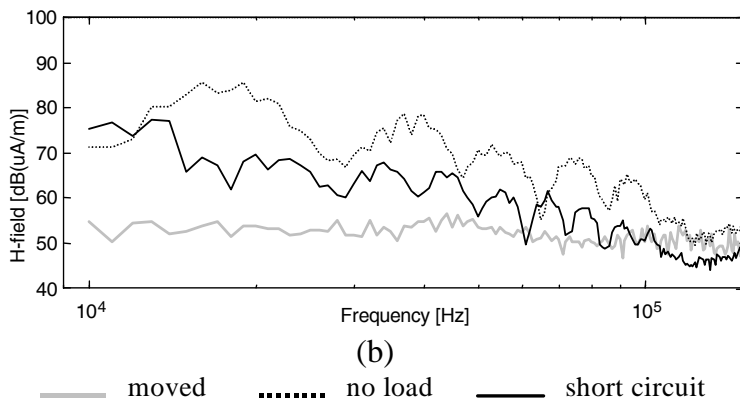

Figure 11: SE_G: H-field at B1 (4 m distance):

(a) along the machine axis and (b) in the vertical axis

Observing Figure 11, it may be noted a periodic behaviour of the magnetic field intensity, which is currently under investigation.

The magnetic field emissions are also measured at two different speed values as shown in Figure 12.

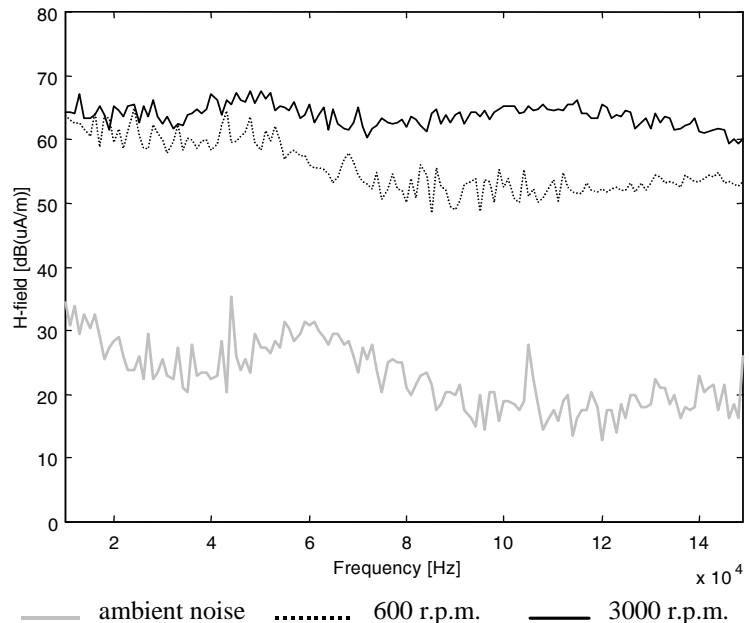

Figure 12: SE_G: $\mathrm{H}$-field at pos. B1 at two speed values

Care must be taken in this case, because at higher speeds correspond higher emissions from the driving dc motor.

\section{EMISSIONS FROM BRUSHLESS SYNCHRONOUS GENERATOR}

The generator characteristics are reported in Table IV.
TABLE IV

SYNCHRONOUS GENERATOR RATED VALUES (BR_G)

\begin{tabular}{|l|c|}
\hline Rated power [MVA] & 93.3 \\
Rated armature voltage [V] & 11500 \\
Rated armature current [A] & 4684 \\
Rated field voltage [V] & 228 \\
Rated field current [A] & 964 \\
Rated speed [rpm] & 3000 \\
Rated frequency [Hz] & 50 \\
\hline
\end{tabular}

The driving dc motor is placed in position C (see Figure 1) and the synchronous generator between $C$ and $D$.

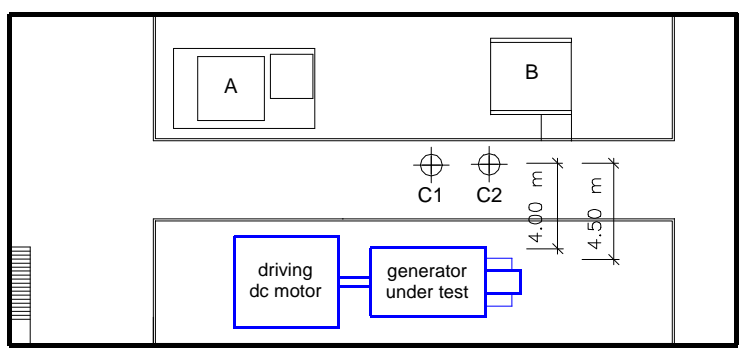

Figure 13: Place of the generator and measuring points

The $\mathrm{H}$-field intensity was measured in three extreme conditions (see Figure 14): "moved" (grey curve), which corresponds to the ambient noise and to the emissions from the driving dc motor; "no load" (dotted curve), which adds the contribution of the field circuit with minimum current flowing into the stator circuit; "short circuit" (solid curve), for which the largest stator current is expected.

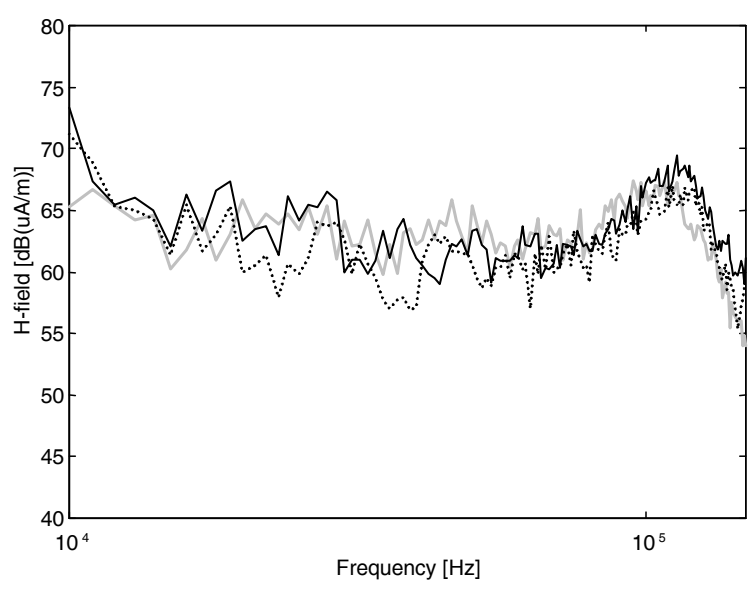

(a) 


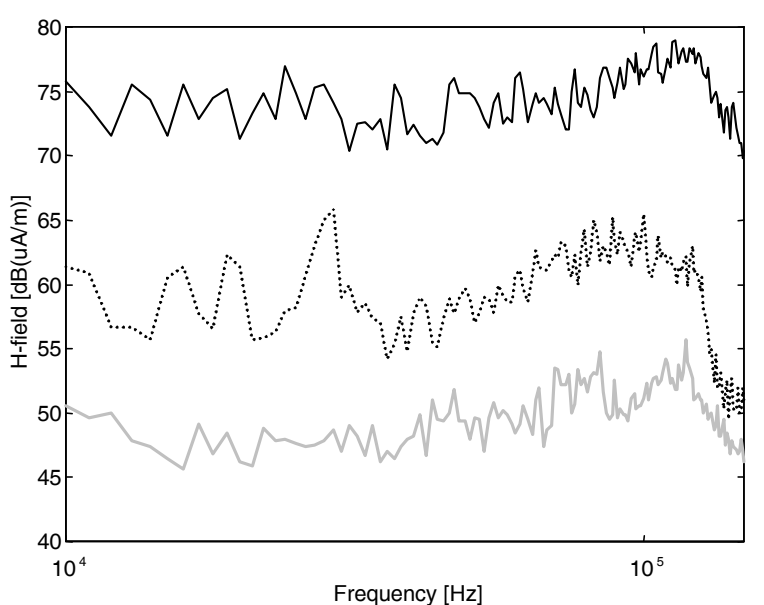

(b)

moved

no loa

short circuit

Figure 14: BR_G: H-field at $4 \mathrm{~m}$ (a) along the machine axis and (b) in the vertical axis

It may be noted that machine magnetic emissions along machine axis (parallel to ground) can't be distinguished from the ambient noise. On the contrary, along the vertical axis the $\mathrm{H}$-field for the "short circuit" test is nearly $15 \mathrm{~dB}$ larger than that in "no load" conditions.

By comparison of Figure 11 and 14 it may be stated that:

- low frequency emissions from brushless are lower than from separately excited machines (the former is also of smaller size);

- the emissions are higher for no-load conditions for the SE_G and for short circuit test for BR_G, so the short-circuit condition is not always the worst case condition for the evaluation of electromagnetic emissions;

- the brushless machine has higher emissions around $100 \mathrm{kHz}$ and above;

- the BR_G has significant emissions (much more disperse for the three tests) in the vertical axis, much higher for the short circuit test;

- a periodic phenomenon is noticed in the SE_G low frequency spectra, much more evident in the no-load condition.

The "moved" curves (which nearly correspond to the emissions of the driving dc motor) are very similar in the SE_G and BR_G cases; so different electromagnetic conditions for the two machines under tests may be excluded.

\section{EMISSION REFERENCE CURVE}

The maximum values of magnetic emissions in the low and medium frequency ranges for the two synchronous generators are collected to define a maximum envelope curve, to be used as reference curve of general use for this kind of machines.
TABLE V

MEASURED MAXIMUM EMISSIONS (BR_G AND E_G)

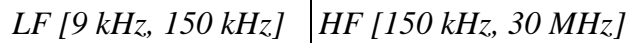

\begin{tabular}{|l|c|c|}
\hline \multicolumn{3}{|c|}{ Separately excited synchronous generator } \\
\hline $\mathbf{E}$ & $65-75 \mathrm{~dB}(\mu \mathrm{V} / \mathrm{m})$ & $100-70 \mathrm{~dB}(\mu \mathrm{V} / \mathrm{m})$ \\
$\mathbf{H}$ & $90-65 \mathrm{~dB}(\mu \mathrm{A} / \mathrm{m})$ & $90-40 \mathrm{~dB}(\mu \mathrm{A} / \mathrm{m})$ \\
\hline \multicolumn{2}{|c|}{ Brushless synchronous generator } \\
\hline $\mathbf{E}$ & - & - \\
$\mathbf{H}$ & $75-80 \mathrm{~dB}(\mu \mathrm{A} / \mathrm{m})$ & $100-50 \mathrm{~dB}(\mu \mathrm{A} / \mathrm{m})$ \\
\hline
\end{tabular}

Medium frequency emissions in the space surrounding the machine are in the reactive near field region; the coupling to victim circuits is mainly inductive for this class of machines [5] and suitable limits are limits on the $\mathrm{H}$-field intensity.

It must be remembered that the machines were set up for test with protecting covers partially removed, so that additional attenuation must be considered, especially at high frequency. Following [8,9] the total shielding effectiveness (SE') may be assumed equal to nearly 30$40 \mathrm{~dB}$.

The measuring distance was always shorter than the 10 $m$ distance indicated in the standards $[3,4]$, so the corrective factor $n$, considering the reactive properties of the fields in the near field region, is for a measuring distance of $4-4.5 \mathrm{~m}$ between $-18 \mathrm{~dB}$ and $-8 \mathrm{~dB}$ for increasing frequency.

The reference curve for $10 \mathrm{~m}$ measuring distance is shown in Fig. 15.

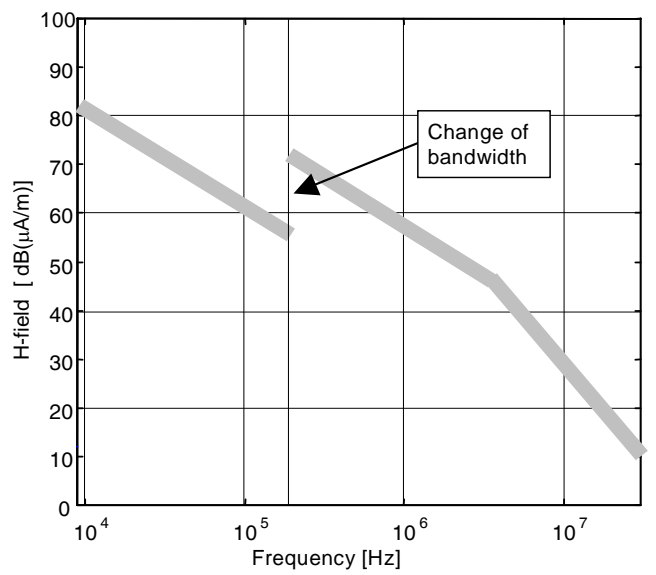

Figure 15: Emission reference curve at $10 \mathrm{~m}$ distance

An important issue is that even at higher frequency (from 10 to $30 \mathrm{MHz}$ ) the wave impedance is still below the free space impedance and limits on the electric field only may be inadequate at $30 \mathrm{MHz}$ and above. Moreover, a large power machine is far from being a localised source, as implicitly assumed when the $10 \mathrm{~m}$ distance limit for far field conditions above $30 \mathrm{MHz}$ is fixed. 


\section{CONCLUSIONS}

Three different rotating machines were analysed over the [9 kHz, $30 \mathrm{MHz}$ ] frequency range at various distances both for electric and magnetic emissions.

The measured E- and H-field are presented and correlated with the machine operating conditions (full load, half load, no load, full speed, half speed, short circuit). The results confirm that: large power electrical machine are a significant source of magnetic emission in the lower frequency range up to nearly some $\mathrm{MHz}$; electric field emission are of concern for commutator machines; short-circuit tests are not always the worst case condition for electromagnetic emission.

The measurement performed on the two synchronous generators are collected and reported to $10 \mathrm{~m}$ measurement distance to obtain a magnetic emission reference curve, available for the definition of suitable limits.

\section{REFERENCES}

[1] N.J. Ryan, D.A. Stone, B. Chambers and P.A. Cudd "Electromagnetic compatibility of electrical machines and drive systems", 30th University Power Engineering Conference UPEC 1995, pp. 141-144.

[2] L.E. Zaffanella, T.P. Sullivan and I. Visintainer "Magnetic fields characterisation of electrical appliances as point sources through in situ measurements”, IEEE Trans. on Power Delivery, v. 12, n. 1, pp. 443-450, Jan. 1997

[3] EN 60034-1/A2, Rotating electrical machines Part 1: Rating and performance, 1997-07

[4] EN 55011, Limits and methods of measurement of radio disturbance characteristic of industrial, scientific and medical (ISM) radio-frequency equipment, 1991-03

[5] A. Mariscotti and P. Pinceti "On site immunity test on supervisory control and data acquisition for industrial electrical power system", Computer Standards \& Interfaces, 21 (1999), pp. 341-347.

[6] CISPR 16, Specification for radio disturbance and immunity measuring apparatus and methods, IEC 1st edition, 1993-08

[7] prEN50121-2, Railway applications Electromagnetic compatibility standards, CENELEC, 1997-09

[8] D.J. White, A handbook on electromagnetic shielding materials and performance, Don White Consultants, 1980.

[9] L.H. Hemming, Architectural electromagnetic shielding handbook, IEEE Press, 1992. 